\title{
La cuestión reforma o revolución en la obra de Rosa Luxemburgo
}

Fecha de entrega: 5 de noviembre de 2018

Fecha de evaluación: 14 de diciembre 2018

Fecha de aprobación: 29 de enero de 2019

\author{
Andrea Paola Buitrago Rojas ${ }^{* *}$
}

\begin{abstract}
El esclavo, en el instante en que rechaza la orden humillante de su superior, rechaza al mismo tiempo el estado de esclavo. El movimiento de rebelión lo lleva más allá de donde estaba en la simple negación. [...] Esa parte de sí mismo que quería hacer respetar la pone entonces por encima de lo demás y la proclama preferible a todo, inclusive a la vida. Se convierte para él en el bien supremo. Instalado anteriormente en un convenio, el esclavo se arroja de un golpe ("puesto que es así...") al todo o nada. La conciencia nace con la rebelión.
\end{abstract}

Albert Camus, El hombre rebelde

* Este trabajo se articula a una investigación desarrollada como proyecto de grado en la Licenciatura en Filosofía y Lengua Castellana de la Universidad Santo Tomás sobre la relación que existe entre la transformación, como propuesta de una política latinoamericana elaborada por Enrique Dussel desde la Filosofia de la Liberación, y la dicotomía expuesta por Luxemburgo entre revolución y reforma. Citar como Buitrago Rojas, A. P. (2019). La cuestión reforma o revolución en la obra de Rosa Luxemburgo. Cuadernos de Filosofía Latinoamericana, 40(120), 89-119. DOI: 10.15332/25005375/5378

* Abogada de la Universidad Santo Tomás, Licenciada en Filosofía y Lengua Castellana de la Universidad Santo Tomás, Magister en Defensa de los Derechos Humanos y del Derecho Internacional Humanitario ante Organismos, Tribunales y Cortes Internacionales en la Universidad Santo Tomás. Docente del Departamento de Humanidades y Formación Integral. Investigadora del Instituto de Estudios Sociohistóricos Fray Alonso de Zamora de la Universidad Santo Tomás. Correo: andreabuitrago@ usantotomas.edu.co 


\section{Resumen}

Este artículo tiene por objeto mostrar el planteamiento elaborado a lo largo de su vida y obra por Rosa Luxemburgo en relación con la dicotomía revolución o reforma. Tal investigación permitió a la autora hacer desde una edad temprana una advertencia sobre el revisionismo y sus peligros en el marco de la socialdemocracia y más específicamente en relación con el proyecto socialista. Igualmente, este análisis permitió una lectura anticipada de las causas y los efectos de la primera y la segunda guerras mundiales sobre el socialismo, al caracterizar las manifestaciones revisionistas dentro del Partido Socialdemócrata Alemán (SPD, por sus siglas en alemán). la conclusión de Luxemburgo es que los métodos reformistas terminaron por subsanar las crisis del capitalismo imposibilitando el desarrollo del proyecto político de un partido revolucionario con una apuesta por el socialismo.

Palabras clave: capitalismo, socialismo, marxismo, revisionismo, transformación política, democracia.

\section{The question of reform or revolution in the work of Rosa Luxemburg}

\section{Abstract}

This article aims to show the approach made throughout the life and works of Rosa Luxemburg in relation to the dichotomy: revolution or reform, a position that allowed the author to make a warning about revisionism and about the dangers that this position would bring within the Social Democracy and, more specifically, on the socialist project. Similarly, this analysis allowed us to face an early reading on the causes and effects of the first and second world war on Socialism, by characterizing the revisionist manifestations within the German Social Democratic Party (SPD) which, by including reformist methods, 
ended up remedying the crisis of capitalism by making the development of the political projects of the revolutionary party impossible from a commitment to Socialism.

Keywords: Capitalism, socialism, Marxism, revisionism, political transformation, democracy.

\section{Introducción}

La obra de Rosa Luxemburgo retoma los postulados que rechazan la construcción moderna del Estado y afirma el paradigma del socialismo científico y el materialismo dialéctico. El socialismo moderno surge de la contraposición de las clases sociales en relación con el contexto histórico. Responde así a la construcción filosófica de Hegel, que comprendió la relación entre sociedad y Estado a partir de la igualdad de la naturaleza humana y de los derechos inalienables del hombre en el reino de la razón y bajo el contrato social.

La conciencia del proletariado toma relevancia en la comprensión de la obra de Luxemburgo al establecer los elementos necesarios para la construcción y el desarrollo del proceso revolucionario. Dicho de otro modo, la autora pretendió identificar las causas de la ausencia de la conciencia proletaria, que determinó el tránsito del camino revolucionario hacia el camino reformista. La conciencia de la realidad social, la situación de la clase y la dinámica de la historia configuran la concepción materialista, la cual permite ubicar la construcción de las condiciones económicas que determinan la existencia de las clases sociales y a partir de allí generan una autocrítica. Se supone que esta última visibiliza la necesidad de la superación de la clases sociales mediante una revolución que conduzca a una ética socialista.

Este artículo da cuenta de una lectura y un análisis bibliográfico de la totalidad de las obras de Rosa Luxemburgo desde la perspectiva de la dicotomía reforma o revolución. Es posible desarrollar este estudio ya que a lo largo de la vida y obra de la autora esta preocupación estuvo latente por el contexto histórico mundial en el que vivió. Particularmete acuciante fue la transformación ideológica y estructural del SPD, cuyas repercusiones sociopolíticas se extendieron hasta después de la Segunda Guerra Mundial. De ahí la importancia del análisis teórico-político que nos plantea 
Luxemburgo tanto para estudiar la historia y la teoría política como para entender las repercusiones de la socialdemocracia en el contexto actual.

La autora propone a lo largo de su obra la reflexión sobre el concepto de revolución como una construcción democrática en la que el poder se configura de abajo hacia arriba y se muestra coherente con los principios marxistas desde el punto de partida hasta el punto de llegada. Esto permite evidenciar cualquier tipo de manifestación revisionista dentro del partido, que al incluir métodos reformistas termina subsanando las crisis del capitalismo, permitiendo por tanto su continuidad y generando un resultado opuesto al perseguido.

Rosa Luxemburgo vislumbró que el tránsito hacia una nueva etapa de la mundialización de ningún modo significaba la pérdida de la centralidad del capital industrial - por la supremacía del capital financiero- - Manteniendo la centralidad de aquel al cuestionar la mundialización capitalista, fue justo ella quien inauguró para la historia del marxismo clásico la crítica a la relación entre capitalismo y militarización, y más aún, a la historia por venir del siglo xx a partir de la herencia de la encrucijada con la que Marx había impugnado la dinámica de largo plazo de la modernidad capitalista: socialismo o barbarie. Aunque exacerbó los límites de la mundialización de su tiempo al caracterizarlos como definitivos, Luxemburgo, como nadie, se adelantó al mirar el siglo xx como el siglo de la barbarie - en el que ciertamente las guerras nunca se detuvieron y solo cambiaron de lugar- (Sánchez, Álvarez y Figueroa, 2014, pp. 42-43).

Lastimosamente la biografía de Luxemburgo nos muestra una vida de persecución y prisión con final en asesinato, todo lo cual condujo a que su propuesta quedara poco trabajada y menos revisada dentro de los análisis políticos y filosóficos de los autores marxistas en su momento. No obstante, autores como Enrique Dussel critican la propuesta de Luxemburgo sobre la oposición/contradicción entre los proyectos reformista y revolucionario como vía para la liberación. De hecho, Dussel propone una vía diferente, la transformación, como camino para la revolución:

Un gran libro de Rosa Luxemburg se denomina Reforma o revolución. Pareciera que ambos conceptos son opuestos. Pero en realidad la cuestión es más compleja. La oposición se encuentra entre "reforma" (A) y "transformación" (B), siendo la revolución (B.b) un modo radical de transformación. La cuestión tiene 
la mayor importancia estratégica. [...] En la tradición de izquierda del siglo $\mathrm{xx}$ se entendió que una actividad que no era "revolucionaria" era "reformista". Si la situación no era objetivamente revolucionaria había que crear por medio de un cierto voluntarismo las condiciones para que adquiriera su fisonomía revolucionaria. Era un idealismo político bajo el nombre de revolución, que algunas veces produjo compromisos extremos en juventudes que inmolaron sus vidas irresponsablemente. (Dussel, 2010, p. 142)

\section{Examen conceptual de la revolución en Luxemburgo}

La gran influencia que tuvo en el terreno del socialismo, sus aportes teóricos a las concepciones marxistas y leninistas, su lucha personal y su dramática muerte contribuyeron a hacer de Rosa Luxemburgo (1871-1919) uno de los referentes de la izquierda del siglo xx. Su conocido dilema, que hoy tiene gran validez, "socialismo o barbarie", sintetiza lo más trascendente de su herencia y lo más importante de su mensaje para el socialismo del siglo xxi. No se trata de una consigna de agitación, presupone una ruptura radical con el modo determinista de comprender la historia y la sociedad, en el cual ella misma había creído hasta ese momento (Beltrán, 2009, p. 21).

La construcción de la transformación política depende de las condiciones históricas de acumulación. Se requiere un modelo económico que satisfaga las necesidades de una población específica obedeciendo a un marco político que determine la estructura del orden social en congruencia con los principios delimitadores de la dirección futura de la sociedad. La ya mencionada dicotomía expuesta en la totalidad de la obra de Luxemburgo busca explicar las dos posibilidades del marco político-económico desde el cual es posible legitimar la estructura social. Los modelos de acción política representan fines excluyentes entre sí, la barbarie o el socialismo respectivamente. La primera posibilidad persigue una evolución social al interior de la continuidad política de la acción imperialista en un modelo económico cuya identidad es el capitalismo; la segunda, busca un modelo político democrático respetuoso de la libertad humana y un modelo económico de tipo socialista.

La organización proletaria no puede ajustarse a un movimiento exclusivo de masas, afirma Luxemburgo, ya que debe perseguir un modelo político, el socialismo. Este requiere una identificación dialéctica de su contrario, el capitalismo, y una delimitación 
de sus principios: la democracia, la libertad, la diferencia, la paz, la propiedad colectiva de los medios de producción. Para la autora un proceso revolucionario debe corresponder con la existencia de condiciones históricas de acumulación, incluidas las crisis económicas que al generar la acentuación de coyunturas políticas impulsan a la población a reconocer con claridad el contexto y los factores de la lucha de clases. La consolidación de la consciencia de clase permite el proceso de identificación del sujeto sociohistórico. La división de clases sociales - burguesía, pequeña burguesía, proletariado y lumpenproletariado- permite determinar las funciones de cada individuo.

La burguesía defenderá el modelo económico capitalista, tal y como lo hizo durante la Revolución francesa de 1789, y como lo ha venido haciendo a lo largo de la historia, tratando de evitar el levantamiento del proletariado y la inestabilidad del orden social establecido. Este rasgo aparece orientado en el discurso del orden, la nacionalidad y la paz universal. La pequeña burguesía se encuentra refugiada en el punto intermedio, entre el proletariado y la burguesía, y sus individuos adoptan el sistema económico capitalista al lograr ascender en la pirámide social. La acción del pequeñoburgués persigue la continuidad del modelo económico y político olvidando su ubicación original. Ese representa el mayor peligro de la lucha de clases pues se produce una confusión en la identificación del sujeto sociohistórico al defender a la burguesía como si se tratara de su clase, lo que deja un campo abierto en la pequeña burguesía, que terminará defendido por otra clase social, a la que no le corresponde dicho rol.

El proletariado, como clase víctima de las condiciones históricas de acumulación, sujeto pasivo del ejercicio político-económico de la burguesía, debe orientar su acción histórica a la ruptura del orden social (en el movimiento). Debe pues conseguir su propia libertad mediante la transformación radical del statu quo enfrentando a su opositor en la acción económico-política y en los discursos ante la opinión pública ya que allí surgen elementos de un escenario aparente que no corresponde con la realidad. En efecto, en este contexto el proletariado cree en la democracia liberal, en su participación política de igual a igual, para evitar la necesidad de una lucha de clases. Cree ubicarse en la pequeña burguesía, por lo que su acción política de defensa se hace desde una clase distinta a la de su identidad material, de modo que deja un vació en la representación y en la acción de la lucha de clases al aislar al sujeto sociohistórico de su predicado, la acción revolucionaria. 
Finalmente, el lumpenproletariado es el conjunto de individuos que no lograron adaptarse al sistema capitalista ni a ninguna de sus clases, así que dejaron de lado el contexto de la producción refugiándose en las calles hasta que culmine su vida.

La democracia en las sociedades comunistas primitivas, los Estados esclavistas de la antigüedad, las comunas medievales, el absolutismo y la monarquía constitucional desembocaron en el capitalismo como instrumento de legitimidad para dar paso a un orden político-económico de tipo absolutista. Luxemburgo exhibe como ejemplo de cimentación de la legitimidad estatal burguesa la figura del sufragio universal, empleada en Alemania para fusionar los pequeños estados.

La reforma y la revolución permiten la evolución de la sociedad de clases puesto que se limitan recíprocamente; son métodos diferentes de desarrollo. La reforma no posee fuerza por sí misma, depende de la revolución inmediatamente anterior, de sus logros y directrices; su punto final es el ejercicio de la siguiente revolución. Por eso es menester expresar que la diferencia entre reforma y revolución no es de carácter temporal, sino de contenido, de sus bases materiales y formales.

El movimiento reformista no busca un camino calmado y lento hacia un objetivo común con la revolución, sino una modificación aparente de la sociedad vigente que permita su continuidad. Mientras tanto, la revolución persigue necesariamente la destrucción de la sociedad actual para generar un nuevo orden.

Luxemburgo rechaza la reforma ya que encuentra en ella la negación de la transformación social, la atenuación y el desarrollo de las contradicciones del sistema capitalista, lo que genera condiciones para su mantenimiento, mas no para su destrucción. Añade la autora que el mayor logro obtenido por el movimiento proletario ha sido el descubrimiento de la construcción teórica de la sociedad capitalista, de lo cual se desprende la necesidad de transformarla hacia el socialismo.

La perspectiva del revisionismo pretende falsamente mostrar una construcción democrática exclusiva del liberalismo burgués, una imagen insostenible si se considera la totalidad de factores políticos involucrados en la construcción de un Estado. Abandonar la perspectiva de la democracia liberal burguesa es una necesidad como ley del proceso histórico ya que la construcción de esta institución dentro de un sistema capitalista conduce a la pérdida de las conquistas verdaderamente democráticas logradas. 
La democracia en el marco socialista aparece como una figura necesaria para la construcción de la clase obrera al crear puntos de apoyo para la transformación del capitalismo. En efecto, es en el ejercicio democrático de sus derechos que el proletariado se puede hacer consciente de sus intereses y de la necesidad de su objetivo histórico. De esta manera es posible comprender la propuesta política de Luxemburgo como propiamente marxista al rechazar la reforma y, por el contrario, mostrar la necesidad de la revolución a partir de la construcción conceptual de la democracia proletaria, elemento proveniente y necesario de la consciencia de clase para impulsar dicha revolución.

La oposición socialista en el parlamento burgués genera una reacción en este y contribuye a la educación de la clase obrera, ya que posibilita el desarrollo de una crítica sistémica que consigue resultados prácticos. Pero no debe tratarse de una búsqueda constante de reformismo social. Ahora bien, cuando esta acción parlamentaria se ve imposibilitada existen tres formas que permiten acentuar el ejercicio de la oposición crítica:

1. Sus consignas deben ser las más avanzadas, de modo que cuando compiten en las elecciones con los partidos burgueses hagan valer la presión de las masas votantes.

2. Deben denunciar constantemente al gobierno ante el pueblo y agitar la opinión pública.

3. Su agitación dentro y fuera del parlamento debe atraer a masas cada vez más numerosas y así convertirse en una potencia con la cual deben contar el gobierno y el conjunto de la burguesía (Luxemburgo, 1976, p. 111).

Los sindicatos y las cooperativas de trabajo asociado son instituciones en las que se posibilita el ejercicio pedagógico de las masas en la acción política. El sindicato - como institución en la que se asocia y se organiza un grupo de trabajadores de una empresa, gremio o actividad económica común- permite la visibilización de las necesidades económicas y laborales de los trabajadores: el salario, el horario laboral, las prestaciones sociales, la protección social en relación con la actividad desempeñada en común. Las exigencias en torno a tales necesidades se abordan en oposición al empleador, propietario de los medios de producción, al ser este responsable de la situación laboral de los trabajadores y tener la posibilidad económica de mejorarla. Las cooperativas 
de trabajadores son instituciones en las cuales se organiza de manera alternativa el trabajo al eliminar la figura del empleador de las jerarquías laborales y presentar una colectivización de los medios de producción y las labores a desempeñar. En estos casos el lucro devengado de la actividad económica correspondiente será proporcional al aporte de cada asociado, de modo que se rechaza la plusvalía -elemento típico del trabajo capitalista-.

Luxemburgo expone que el partido es una institución político-económica encargada de la agitación y organización del socialismo, el régimen de libertades políticas, el rol del intelectual dentro del partido, los aspectos económicos como referentes de las causas sociales del movimiento proletario, la correspondencia de sus estatutos con la corriente histórica a la que pertenece, la determinación de los peligros y la obtención del triunfo revolucionario. La agitación y organización del socialismo es una función prioritaria del partido, según dice la autora, ya que es así como se generará una incidencia en cualquier coyuntura política a la que deba responder la organización, de modo que ha de consolidarse como elemento indispensable para el proceso revolucionario. Es decir, ante un situación de crisis económica en el modelo capitalista la agitación organizada debe dirigir una acción sobre la población planteando como única alternativa el socialismo. Dicha tarea requiere de un límite temporal de corta duración ya que durante este periodo la clase dominante buscará eliminar la crisis con todos sus medios - políticos, económicos, sociales o culturales- para evitar la disolución del orden establecido. Ello implica la necesidad de una institución que actúe con rapidez, agudice la crisis y produzca una situación histórica especial para el desarrollo de la revolución.

Aquí también nos encontramos ante una de las grandes leyes históricas de la revolución, frente a la que se estrellan todas las habilidades y sabidurías de los pequeños "revolucionarios" al estilo de los del SPD, que en cada lucha solo se afanan por buscar una cosa: pretextos para la retirada. Una vez que el problema fundamental de una revolución ha sido planteado con total claridad - y la revolución que enfrenta Luxemburgo debe empezar por el derrocamiento del gobierno Ebert-Scheidemann, en tanto que primer obstáculo para la victoria del socialismo-, no deja de aparecer una y otra vez en toda su actualidad y con la fatalidad de una ley natural. Todo episodio aislado de la lucha hace aparecer el problema en todas sus dimensiones por poco preparada que esté la revolución para darle solución, por poco madura que sea todavía la situación. “¡Abajo Ebert-Scheidemann!” es la consigna que aparece inevitablemente a cada crisis 
revolucionaria de la Alemania de la época, en tanto que única fórmula que agota todos los conflictos parciales y que por su lógica interna, se quiera o no, empuja todo episodio de lucha a sus más extremas consecuencias (Luxemburgo, 1999).

El régimen de libertades políticas que debe plantear el partido aparece en el análisis del proceso revolucionario en Rusia. Es indispensable una institución de poder cuyo ejercicio corresponda con la dirección de abajo hacia arriba, y no como en el centralismo de partido planteado por Lenin, de arriba hacia abajo. De ser como lo quiere Lenin, se produciría una inestabilidad social y política que generaría un objetivo inverso al perseguido. Es relevante la consolidación del partido como institución que posibilite el ejercicio de la libertad democrática de sus miembros, además de permitir el desarrollo de distintas corrientes de opinión dentro de aquel. Al fin y al cabo, el debate y la autocrítica temprana generarán las condiciones de continuidad del movimiento obrero al permitir una corrección rápida de los posibles errores de la acción política revolucionaria.

El rol del intelectual dentro del partido debe coincidir con la construcción epistemológica de la sociedad burguesa, que ha consolidado perspectivas científicas y culturales cuyo objeto es perseguir la continuidad del sistema capitalista. Lo anterior corresponde con el sujeto sociohistórico, que posee una capacidad económica de consumo y acceso al conocimiento científico. Incluso el carácter del tiempo libre para el desarrollo de ese conocimiento implica necesariamente la consolidación de una lógica de clase burguesa. Es obligatorio continuar con dicho proceso epistemológico, nos dice Luxemburgo, pero deberá corresponder con la necesidad de afrontar nuevas condiciones históricas en las que se visibilice la búsqueda de la liberación de la clase proletaria. De ahí que el intelectual sea quien tenga la obligación de integrar y participar en el partido revolucionario, al igual que la de desarrollar una ciencia que construya la organización, los principios, la conciencia de clase y la revolución.

La correspondencia entre los estatutos del partido y la corriente histórica, por su parte, no puede ser el producto de una mera arbitrariedad de las decisiones del comité central del partido, sino que es y debe ser el producto de las necesidades históricas.

Incluso dentro de estos límites los obreros en la sociedad actual pueden avanzar solo en la medida en que creen las armas intelectuales que necesitan en la lucha por su liberación. Pero esta reserva le impone a la clase obrera (mejor dicho, a los intelectuales 
de la clase obrera) márgenes muy estrechos en el campo de la actividad reflexiva. Toda su energía creadora está relegada a una rama específica de la ciencia, la ciencia social (Luxemburgo, 1999, p. 116).

\section{El método de la huelga de masas en la revolución}

La huelga de masas tiene su origen en la teoría anarquista, donde se prevé que en una única acción la totalidad de los obreros del mundo se volcarán en contra de sus empleadores, lo que cambiará instantáneamente el orden social a nivel mundial. A Luxemburgo esta hipótesis le parece bastante espuria ya que los gobiernos del mundo impedirían a toda costa dicha situación. Así pues, es innecesario reflexionar mucho alrededor de dicha propuesta.

Si algo nos enseña la Revolución rusa es sobre todo que la huelga de masas no se "fabrica" artificialmente, que no se "decide" al azar, que no se "propaga". Es un fenómeno histórico que en un momento dado surge de las condiciones sociales como una inevitable necesidad histórica:

No se trata de la crítica subjetiva de la huelga de masas desde la perspectiva de lo que sería deseable, sino de la investigación objetiva de las causas de la huelga de masas desde la perspectiva de lo históricamente inevitable. (Luxemburgo, 1999, p. 165)

Luxemburgo añade la experiencia de la Revolución rusa como muestra práctica de que el ejercicio de la huelga de masas no genera un cambio instantáneo del orden. Así se demuestra la falsedad de la teoría anarquista y su construcción ilusoria que excluye la realidad fáctica. Sin embargo, para la autora la huelga de masas no queda como un elemento inservible, todo lo contrario, permite ubicar una fase económica en la conciencia de las masas, a partir de la cual es posible generar una conciencia política que es condición necesaria para la acción revolucionaria.

La ley del movimiento de estos fenómenos aparece claramente: no radica en la huelga de masas misma ni tampoco en sus particularidades técnicas, sino en las relaciones de fuerza políticas y sociales de la revolución. La huelga de masas es simplemente la forma de la lucha revolucionaria, y todo cambio en la relación entre las fuerzas en pugna, en el desarrollo de los partidos, en la división de clases y en la posición de la 
contrarrevolución influye inmediatamente sobre la acción huelguística a través de miles de caminos invisibles y apenas controlables. Sin embargo, la acción huelguística en sí no cesa en ningún momento. Cambian únicamente sus formas, su extensión, su repercusión. Es el pulso vivo de la revolución y al mismo tiempo su fuerza motriz más poderosa. En otras palabras: la huelga de masas, tal como nos la muestra la Revolución rusa, no es un medio astuto, ingeniado con el fin de lograr una actuación más poderosa en la lucha proletaria, sino el mismo movimiento de las masas obreras, la forma en que se manifiesta su lucha en la revolución (Luxemburgo, 2003, p. 56).

La acción inicial de la lucha de masas permite a nivel parlamentario la concentración sobre un objetivo legislativo para la conquista de los derechos políticos y de condiciones salariales dignas. De igual modo, la huelga de masas es pertinente ante regímenes absolutistas, aunque en este contexto requiere más educación política de dichas masas, mayor conciencia de clase y una cuidadosa organización estratégica para derribar el régimen.

Para Luxemburgo el actor político más importante es la masa, aunque no se hacía ilusiones acerca de la constancia de sus objetivos y sus capacidades de actuación:

No hay nada tan mutable como la psicología de los hombres. Al igual que la psique del hombre, la psique de las masas encubre siempre, en estado latente -como Thalassa, el mar eterno-, todas las virtualidades: una calma mortal y la tempestad más feroz, la cobardía más vil y el más bravo heroísmo. Las masas son siempre aquello que necesariamente tienen que ser, en función de las circunstancias, y siempre están a punto de convertirse en algo totalmente diferente de lo que aparentan ser. ¡Como un torpe capitán que dirige su rumbo sólo según el aspecto momentáneo de la superficie del agua y no sabe interpretar las señales del cielo y de la profundidad del mar para prever la intemperie que se avecina! (Gambina, Rajland y Campione, 2002, p. 16)

La autora también muestra la diferencia entre la huelga de masas y la huelga de protesta. La primera constituye una forma de lucha revolucionaria que permite el movimiento de la masa y la indicación de la existencia de un periodo de lucha de clases. La segunda es una forma superior de la huelga de masas, que expresa una disciplina partidaria ante una dirección consciente sustentada en una reflexión política previa sobre la acción de las masas. Allí se ubica el comienzo de un levantamiento revolucionario. 
Luxemburgo veía la espontaneidad como la forma revolucionaria de oponerse a esa burocracia sindical. Según ella la acción revolucionaria debía pasar por un auténtico movimiento de masas y no por el estrecho marco del aparato del SPD y los sindicatos. Las huelgas deberían tener como primer objetivo el derrocamiento del Estado burgués, por lo que el problema de la organización no debería ser asunto de la jefatura sindical, sino que estaría en función de la interacción entre el movimiento global de la clase obrera y el grado de desarrollo de la conciencia de clase en un momento dado (Huelga de masas, partido y sindicato, 2003 [1906]). "Un concepto rígido, mecánico y burocrático sólo reconocerá la lucha como producto de cierto nivel de organización. Por lo contrario, los desarrollos dialécticos en la vida real crean organizaciones como producto de la lucha" (Luxemburgo, citada en Dunayevskaya, 1985). Pero Luxemburgo se enfrentaba a la jefatura sindical no solo porque esta era conservadora, sino porque únicamente se preocupaba por los obreros organizados, no por los no organizados —desde lo que se dio en llamar lumpenproletariado (las capas urbanas más pobres y excluidas del proceso productivo directo, hoy en día trabajadores marginales y peor retribuidos) hasta los artistas-, tan revolucionarios como el proletariado. Es decir, los sindicatos no tendrían, según Luxemburgo, más finalidad que hacer surgir la conciencia revolucionaria de los trabajadores (Perdices de Blas y Gallego, 2009, p. 240).

La unidad de acción es relevante en la huelga de masas. A pesar de existir diferencias políticas entre los partidos y sindicatos, debe haber una cohesión que evite la caída temprana del movimiento. Han de detectarse los partidos y sindicatos con base reformista ya que suelen expresar su negativa ante la huelga de masas pues saben de antemano que en el ejercicio de esta se encuentra un proyecto revolucionario.

$\mathrm{Al}$ respecto, las únicas medidas efectivas en manos de la revolución proletaria son de carácter político y social: transformar lo más rápido posible la vida de las masas y despertar el idealismo revolucionario, que puede mantenerse durante un largo lapso si las masas llevan una vida intensamente activa en las condiciones de una ilimitada libertad política (Luxemburgo, 2003, p. 64).

La convicción revolucionaria se aferra a una opción de liberación basada en principios y condiciones históricas de la acción política que se relacionan con una fase económica y una política. La fase económica corresponde al cambio en los modos de producción y la fase política, a una internacionalización de la revolución bajo un mando democrático. Solamente al comprenderse el anterior proceso es posible hablar del triunfo 
de la revolución: la destrucción de la sociedad vigente y su sutitución por un nuevo orden social, que en la propuesta teórica de Luxemburgo coincidirá necesariamente con el orden socialista.

\section{Examen conceptual de la reforma en Luxemburgo}

Luxemburgo se pregunta: “ $¿$ Es posible que la socialdemocracia se oponga a las reformas? ¿Podemos contraponer la revolución social, la transformación del orden imperante, nuestro objetivo final, a la reforma social?” (Luxemburgo, 1999, p. 74). Y responde de inmediato: "De ninguna manera" (Luxemburgo, 1999, p. 74). Bernstein, en su búsqueda de la renuncia a la transformación social y su apuesta por la reforma, niega por completo la revolución en el movimiento político. Así, reforma o revolución constituyen el ser o no ser de la transformación:

Es por ello que quienes se pronuncian a favor del método de la reforma legislativa en lugar de la conquista del poder político y la revolución social [...], en realidad no optan por una vía más tranquila, calmada y lenta hacia el mismo objetivo, sino por un objetivo diferente. [...] Siguiendo las concepciones políticas del revisionismo, llegamos a la misma conclusión que cuando seguimos las concepciones económicas del revisionismo. Nuestro programa no es ya la realización del socialismo sino la reforma del capitalismo; no es la supresión del trabajo asalariado, sino la reducción de la explotación, es decir, la supresión de los abusos del capitalismo en lugar de la supresión del propio capitalismo. (Luxemburgo, 1976, p. 49)

Así pues, la autora ubica dos modelos de acción política distintos, la revolución y la reforma, los cuales corresponden con objetivos económico-políticos distintos. La reforma persigue la modificación superficial de la sociedad; la revolución, la instauración de una nueva sociedad. El programa de la reforma apunta a la reducción de la explotación, la supresión de los abusos laborales y el mejoramiento de la clase obrera dentro del capitalismo, mientras que la revolución como programa persigue correspondientemente la supresión total del trabajo asalariado, la realización del socialismo y la eliminación del capitalismo.

Solamente encontramos otra oposición entre ambos momentos del movimiento en la teoría de Eduard Bernstein, que queda expuesta en su serie de artículos “Problemas del 
socialismo", publicada en la Neue Zeit en los años 1897 y 1898, y muy especialmente en su libro Las premisas del socialismo y las tareas de la socialdemocracia. Prácticamente toda su teoría se reduce a aconsejar el abandono del objetivo final de la socialdemocracia, la revolución social, y convertir el movimiento de reforma, que es un medio, en el fin de la lucha de clases. El mismo Bernstein ha concretado maravillosamente sus puntos de vista en la frase: "Para mí, el fin, sea cual sea, no es nada; el movimiento lo es todo". Pero como quiera que el objetivo final es precisamente lo único concreto que establece diferencia entre el movimiento socialdemócrata, por un lado, y la democracia y el radicalismo burgueses, por otro; y como ello es lo que hace que todo el movimiento obrero pase de una cómoda tarea de remendón encaminada a la salvación del orden capitalista, a una lucha de clases contra este orden buscando su anulación, tenemos pues que este dilema de reforma o revolución es al mismo tiempo, para la socialdemocracia, el de "ser o no ser" (Luxemburgo, 1976, p. 6).

Bernstein, principal defensor del reformismo, refutó las premisas del socialismo científico negando la autodestrucción del capitalismo, la concepción materialista de la historia y la necesidad de la revolución. Por el contrario reivindicó la reforma gradual del sistema capitalista mediante las cooperativas de consumo, los sindicatos y la extensión gradual de la democracia participativa, elementos expuestos en su libro ya mencionado, donde muestra que la gran capacidad de adaptación del capitalismo favorece la desaparición de las crisis generales pues evita la revolución mediante el sistema de crédito, las organizaciones patronales, los medios de comunicación y el servicio informativo, la variedad de la producción y el incremento de la clase media. Las cooperativas y los sindicatos propuestos por la acción reformista de Bernstein reflejan la lastimosa falta de propósito de los movimientos o asociaciones sindicales.

El rechazo al socialismo científico se compone de tres puntos: 1) la anarquía de la economía capitalista, 2) la socialización progresiva del proceso de producción y 3) la organización y conciencia de la clase proletaria como factor activo de la revolución. Al eliminar la teoría del colapso y el presupuesto teórico de la existencia del proletariado ya no se requiere construir la consciencia de la clase proletaria ni conceptualizar la socialización de la producción, y en consecuencia se excluye la revolución.

Contra las pesadillas de Bernstein acerca del efecto fatal que resultaría de que el proletariado tratase de conquistar el poder político "prematuramente", Luxemburgo sostuvo: 
Como el proletariado no estaba en posición de adueñarse del poder político más que 'prematuramente', como el proletariado se ve absolutamente obligado a adueñarse del poder una o varias veces 'demasiado pronto' antes de mantenerse para siempre en el poder, la objeción - esa toma 'prematura' del poder- no es en el fondo más que una oposición general a la aspiración del proletariado de adueñarse del poder estatal. (2017b, p. 88)

Y contra la demanda de Bernstein de que se suprima "la estructura dialéctica" de las teorías de Marx, escribe:

Cuando él dirige sus flechas más certeras contra nuestro sistema dialéctico, realmente está atacando el modo específico de pensamiento empleado por el proletariado consciente en su lucha por la liberación. Es un intento por sacudir el brazo intelectual con ayuda del que el proletariado, aunque materialmente bajo el yugo de la burguesía, sin embargo se ve capacitado a triunfar sobre la burguesía; pues es nuestro sistema dialéctico el que... ya está realizando una revolución en el dominio del pensamiento. (Luxemburgo, citada en Dunayevskaya, 1985, p. 15)

Esta teoría tuvo un fuerte desarrollo dentro del SPD, que Luxemburgo tomó como base para construir su propia teoría sobre la referida dicotomía, durante el desarrollo de la Primera Guerra Mundial y el periodo de entreguerras, según expresa la obra bibliográfica de la autora. En efecto, durante la Primera Guerra el reformismo logró desviar el rumbo del proceso revolucionario y lo ubicó como un objetivo secundario, al priorizar el discurso de la defensa nacional, la paz, la seguridad y el orden y ubicar, en consecuencia, como única posibilidad la reforma gradual al sistema, es decir, adaptarse al capitalismo. La respuesta de Luxemburgo ante el carácter reformista y la estructura de los sistemas económicos propuestos consistió en concentrarse en el sistema crediticio y su centralidad como factor de adaptación de la economía capitalista para extender la producción y facilitar el intercambio monetario. El crédito se presenta como solución en la conducción de las crisis económicas ya que el empresario tiene así un acceso directo al capital de los demás. A ello se añade la utilización audaz e inescrupulosa de la propiedad ajena, que conduce al problema de la especulación.

Además, continúa Luxemburgo, 
no es cierto que el socialismo surgirá automáticamente de la lucha diaria de la clase obrera. El socialismo será consecuencia de (1) las crecientes contradicciones de la economía capitalista y (2) la comprensión por parte de la clase obrera de la inevitabilidad de la supresión de dichas contradicciones a través de la transformación social. Cuando, a la manera del revisionismo, se niega la primera premisa y se repudia la segunda, el movimiento obrero se ve reducido a un mero movimiento cooperativo y reformista. Aquí nos desplazamos en línea recta al abandono total de la perspectiva clasista. [...] Pero, por otra parte, lo que constituye precisamente el eje del revisionismo y lo distingue de la posición sustentada hasta el momento por la socialdemocracia es que no basa su teoría en la creencia de que el desenvolvimiento lógico del sistema económico imperante resultará en la supresión de las contradicciones del capitalismo. [...] No propone eliminar esas contradicciones mediante una transformación revolucionaria. Quiere disminuir, atenuar las contradicciones capitalistas. De modo que el antagonismo que existe entre la producción y el cambio se reducirá mediante la terminación de las crisis y la formación de cárteles capitalistas. El antagonismo entre el capital y el trabajo será resuelto mejorando la situación de la clase obrera y conservando las clases medias. Y la contradicción entre el Estado clasista y la sociedad quedará liquidada a través del incremento del control estatal y el progreso de la democracia. (Luxemburgo, 1976, p. 29)

El reformismo apareció dentro del partido revolucionario durante el 4 de agosto de 1914, como manifestación del desangramiento de la sociedad capitalista al inicio de la Primera Guerra Mundial. Encontró su justificación, entre otros motivos, en la invasión de tropas rusas a Alemania, el bombardeo de Núremberg por los franceses y el envenenamiento de los pozos de Montsigny por parte de un médico francés:

La escena ha cambiado totalmente. La marcha de seis semanas sobre París se ha convertido en un drama mundial. El asesinato en masa se ha convertido en una tarea monótona, pero la solución final no parece estar más cerca. El capitalismo ha quedado atrapado en su propia trampa y no puede exorcizar el espíritu que ha invocado. Ha pasado el primer delirió. Pasaron los tiempos de las manifestaciones patrióticas en la calle, de la persecución de automóviles de aspecto sospechoso, los telegramas falsos, de los pozos de agua envenenados con el germen del cólera. Ya terminó la época de las historias fantásticas 
de estudiantes rusos que arrojan bombas desde los puentes de Berlín, o de franceses que sobrevuelan Núremberg; se acabaron los días en que el populacho cometía excesos al salir a cazar espías, de las multitudes cantando, de los cafés con coros patrióticos; no más turbas violentas, prestas a denunciar, a perseguir mujeres, a llegar hasta el frenesí del delirio ante cada rumor; se ha disipado la atmósfera del asesinato ritual, el aire de Kishinev, que hacía que el vigilante de la esquina fuera el único representante que quedaba de la dignidad humana. El espectáculo ha terminado. (Luxemburgo, 1976, p. 29)

El estado decadente del capitalismo es un hecho que necesita exteriorizarse y criticarse, afirma la autora, ya que tal descripción crítica permite la continuidad del movimiento impulsado por el proletariado internacional ante la lamentable situación histórica que tiene que afrontar: la capitulación de la socialdemocracia. Este crudo análisis de la situación del partido ante la Primera Guerra Mundial tiene un carácter de necesidad e inmediatez ya que, según postula Luxemburgo, sería aún más peligroso cerrar los ojos:

Supongamos un instante, para seguir la discusión e investigar el fantasma de las "guerras nacionales" que controla en este momento la política socialdemócrata, que en uno de los Estados beligerantes la guerra fuera, al comienzo, una guerra de defensa nacional. El éxito en el terreno militar exigiría la ocupación inmediata de territorio enemigo. Pero la influencia de grupos capitalistas interesados en la anexión imperialista despertará apetitos imperialistas a medida que prosigue la guerra. La tendencia imperialista que al comienzo fue, quizá, embrionaria, crecerá y se desarrollará en el invernadero de la guerra y en poco tiempo determinará su carácter, fines y resultados. (Luxemburgo, 2017a, p. 174)

La autocrítica aparece tras los errores cometidos dentro del SPD con ocasión de la Primera Guerra Mundial: fue necesario aceptar el cambio del contexto mundial ya que la guerra alteró los lugares de la acción histórica, pero se hizo en el sentido de sustituir las luchas de las clases sociales por las luchas mundiales de las naciones. A partir de allí, Luxemburgo objeta que el SPD alemán debió llevar a su proletariado a la dirección del pueblo internacional asumiendo el conflicto mundial como reiteración del capitalismo, al cual era necesario confrontar con la lucha mundial de los trabajadores. Al actuar de manera contraria a esta última recomendación, la guerra terminaría por derrumbar 
la construcción política del proletariado internacional. Por eso Luxemburgo lamentó profundamente la postura tomada el 13 de julio de 1914 por parte del órgano central de la socialdemocracia de respaldar al Gobierno alemán en la guerra:

El proletariado socialista rechaza toda responsabilidad por los acontecimientos precipitados por una clase dominante ciega y al borde de la locura. Sabemos que para nosotros surgirá una nueva vida de las ruinas. Pero la responsabilidad recae sobre los gobernantes actuales. ¡Para ellos, se trata de su existencia misma! ¡Es el juicio final de la historia mundial! (Luxemburgo, 1976, p. 272)

Después del inicio de la guerra y tras legitimarla, la siguiente pregunta que debe responder el SPD es en torno a la acción política en el marco del conflicto: ¿Cómo conducirse durante la guerra? Dicha pregunta es necesaria puesto que, más allá de mostrar una postura favorable o desfavorable frente a las acciones bélicas, lo que debe buscarse es la guía del proletariado internacional ante dicho peligro. Luxemburgo insiste en que se debe actuar de manera distinta a los postulados expresados por la dirección: sin interrumpirse, ni suspenderse la lucha de clases internacional mientras pasa la guerra. No se debe votar favoreciendo las posturas nacionalistas que encabeza el gobierno, sino denunciar cualquier tipo de violencia y aprovechar el abismo generado entre la solidaridad internacional de los pueblos del mundo y los intereses de independencia y libertad de las naciones que exigen la muerte y la brutalidad armada.

En el V Congreso de la II Internacional, celebrado en París en 1900, se debatió ampliamente el papel de los países en relación con los más pobres, y en concreto, con las colonias. Rosa Luxemburgo aseguró allí que "el militarismo, el imperialismo, el nacionalismo y la política colonial de las grandes potencias son aspectos de un mismo fenómeno que amenaza con una guerra a gran escala" (Luxemburgo, 1986[1900], p. 213). Lamentablemente, sus palabras resultaron premonitorias y en 1914 estalló la gran guerra al tiempo que se produjeron rupturas definitivas. No solo entre el ala más izquierdista de la socialdemocracia alemana y sus compañeros socialistas, sino entre los partidarios de la paz y el internacionalismo en Europa (convertidos en escasa minoría) y los que finalmente se alinearon con sus gobiernos en la Primera Guerra Mundial. Luxemburgo abandonó el SPD cuando este votó a favor de los créditos de guerra propuestos por el gobierno de Guillermo II, lo que motivó su posterior acusación y encarcelamiento por alta traición (Berbel, Cárdenas y Paleo, 2014, p. 108). 
La necesidad de analizar lo ocurrido el 4 de agosto de 1914 como producto de las amenazas contra Serbia; los intereses de Austria-Hungría; la aventura del asíllamado Partido Belicista austriaco, apoyado en su plenitud por el gobierno de Alemania según lo expresa su Libro Blanco de la época, el hecho de que ya en esta fecha las fuerzas alemanas habían invadido a Bélgica; todo ello expresaría que el mundo había estado preparándose durante décadas para la beligerancia. Una guerra llevada a cabo con el interés de desestimular cualquier tipo de invasión extranjera, a fin de proteger el ideal de patria y libertad, además de oponerse al despotismo ruso viniera de la esquina política que fuera.

Luxemburgo lamenta la declaración de la socialdemocracia en la que esta rechaza el zarismo y firma su adhesión a la lucha por la cultura europea y la defensa de la nación alemana en tiempos de guerra. Para la autora todo eso representa un problema de actitud dentro del partido al amparar un programa por la paz civil que pone por encima de todo el principio de unidad nacional como el mayor deber de la población alemana, de modo que la lucha de clases concluiría hasta la consumación de la guerra. ¿Qué se alteró al producirse la guerra? Los derechos de los propietarios, la explotación, el dominio de clase y la opresión política perduraron inmunes, lo que cambió fue que con la aceptación de la paz civil y la guerra por parte del SPD de Alemania se aceptó la implementación de un gobierno militar justificado a partir del principio socialista de la autodeterminación de las naciones, con lo cual quedó suspendida la vigencia de la lucha de clases y el partido terminó por negar la finalidad de su existencia.

El SPD alemán no garantizó la continuidad de la democracia, afirma Luxemburgo, ya que aceptó la usurpación de la libertad de prensa, el estado de sitio y la posibilidad de publicar en sus propios órganos de prensa la postura política del Gobierno bajo la justificación de la defensa del país. El efecto logrado fue el opuesto al buscado. El socialismo internacional reconoce el derecho de las naciones libres e independientes y la igualdad de derechos, pero dentro de la órbita del socialismo ya que solo desde allí es posible afirmar estos presupuestos de manera conjunta. La justificación de la protección de la patria previa a la lucha de clases solamente impide y obstaculiza el proceso de reconocimiento del socialismo internacional ya que elimina a su vez el reconocimiento de la igualdad de derechos, y termina decantándose por la independencia de una nación mas no por la de la totalidad de las naciones: 
Hoy la nación no es sino un manto que cubre los deseos imperialistas, un grito de combate para las rivalidades imperialistas, la última medida ideológica con la que se puede convencer a las masas de que hagan de carne de cañón en las guerras imperialistas. Esta tendencia general del capitalismo contemporáneo determina las políticas de los Estados individuales como su ley suprema y ciega, así como las leyes de la competencia económica determinan las condiciones de producción del empresario individual. (Luxemburgo, 1976, p. 316)

Luxemburgo retoma la teoría de Kautsky que expresa la imposibilidad de conciliar el patriotismo burgués y el proletario ya que una unificación en busca de una protección del pueblo aparece bastante alejada de la realidad: el partido revolucionario no puede ubicarse al servicio del Estado clasista ni debe esperar silenciosamente al fin de la guerra; lo que debe buscar es defender la autodeterminación nacional en vez de la autodefensa nacional. Asimismo, debe buscar la forma de eliminar todo tipo de agresión para lograr un incremento en la libertad política mediante la construcción de consignas que den claridad al proletariado al dirigirlo por el sendero de la eliminación de la guerra.

Las advertencias de Luxemburgo sobre los peligros de una caída en la barbarie se repitieron en discursos y escritos, pero no se captó toda su gravedad. No existía una imagen de lo que podría significar la caída en la barbarie. Solamente la victoria de los bárbaros hitlerianos mostró con brutal precisión que las advertencias de Luxemburgo eran algo más que un recurso retórico. La destrucción del movimiento obrero, la atomización de los estratos sociales, las quemas de libros, la represión de la vida intelectual, el horror de los campos de concentración, la devastación de sectores enteros de la población, el dominio completo de la sociedad por el aparato estatal, la guerra total con la inevitable derrota total y sus terribles consecuencias, todo eso fue la realización de la barbarie (Frölich, 1976, p. 16).

La paz se concibe en relación con la realización de la revolución mundial del proletariado, como efecto de la victoria de este, del socialismo y de la libertad humana. Se concibe un solo camino para la victoria de la revolución, ubicado por la autora en el plano económico. De ahí se resalta la importancia de la extensión del socialismo al campesinado para la total transformación de la economía: 
La idea directriz de la transformación económica que construirá el socialismo es la abolición de la diferencia y contraste entre la ciudad y el campo. Esta separación, este conflicto, esta contradicción es un fenómeno puramente capitalista, y debe desaparecer apenas asumimos el punto de vista socialista. (Luxemburgo, 1976, pp. 431-432)

\title{
La necesidad de realizar una crítica de la Revolución rusa
}

Luxemburgo pasa a situar el proceso revolucionario en dos momentos específicos. El primero se encuentra sujeto a la ley de la determinación histórica, la cual permitirá la llegada a la meta esperada, la revolución. Sin embargo, esta etapa se ubica meramente en el campo político, una etapa infantil e inmadura del proceso socialista. Esta requiere necesariamente de una fase económica:

\begin{abstract}
The proletarian revolution that has now begun can have no other goal and no other result than the realisation of socialism. The working class must above all else strive to get the entire political power of the state into its own hands. Political power, however, is for us socialists only a means. The end for which we must use this power is the fundamental transformation of the entire economic relations. (Luxemburgo, 1970, p. 4)
\end{abstract}

Toda vez que la esencia de la revolución está en el carácter económico de las luchas socialistas, cobra sentido la primacía de las huelgas. Su carácter continuo permitiría la construcción del camino revolucionario y el triunfo de una verdadera revolución socialista solo puede vislumbrarse a partir de la lucha de las masas:

\footnotetext{
Queda claro entonces que en toda revolución solo podrá tomar la dirección y el poder el partido que tenga el coraje de plantear las consignas adecuadas para impulsar el proceso hacia adelante y de extraer de la situación todas las conclusiones necesarias para lograrlo. (Luxemburgo, 1976, p. 25)
}

Esto se explica al examinar la imposibilidad del socialismo de generarse por mero decreto de un gobierno socialista; su surgimiento solamente puede partir de la construcción política y económica de las masas. Así, Luxemburgo se pregunta: “¿Cuál 
es la forma eterna de la lucha por el socialismo?” (1976, p. 427). Y acto seguido ella misma contesta, con motivo de la fundación del Grupo Espartaco, germen del Partido Comunista Alemán: "La huelga”.

Así pues, el segundo momento de la revolución se encuentra en la huelga, donde radicará el factor decisivo de la revolución al dejar a un lado la cuestión política y asumir su principal consecuencia, la intensificación de la lucha económica:

\begin{abstract}
Ahora bien, yo considero que la esencia misma de la revolución reside en que las huelgas se extenderán más y más, hasta constituir, por fin, el foco de la revolución. [Aplausos] Así tendremos una revolución económica y, junto con ello, una revolución socialista. La lucha por el socialismo debe ser librada por las masas, solo por las masas, frente a frente con el capitalismo; se tiene que librar en todos los lugares de trabajo, cada proletario contra su patrón. Solo así podrá ser una revolución socialista. (Luxemburgo, 1976, p. 426)
\end{abstract}

Ahora bien, no es de extrañar que haya dificultades para predecir lo que ocurrirá durante el segundo acto de la revolución con la constitución de una nueva institución que permita la educación de la clase obrera, tras lo cual seguirá la conformación de la Asamblea Nacional. Al fin y al cabo, concluye Luxemburgo, un sistema socialista es el producto histórico de una experiencia viviente y su relación con las necesidades sociales en la búsqueda de medios que permitan satisfacerlas. La experiencia aparece entonces como el ámbito que permite la corrección y la apertura del camino para la liberación de la humanidad.

\title{
Las tareas del partido revolucionario
}

La última intervención de Rosa Luxemburgo en su vida pública fue en la fundación del Partido Comunista Alemán, donde desarrolló una reflexión sobre los pilares necesarios del programa del partido. Allí respondió al asunto de la dicotomía reforma vs. revolución como lo había hecho a lo largo de su vida. Los cinco puntos que expuso pueden resumirse en la importancia de fortalecer la educación del proletariado en la participación dentro del partido para que a lo largo de la acción política pudieran identificar la necesidad de diferenciar el sentido de la reforma y el de la revolución. 
El discurso pretendió mostrar la evolución de la clase obrera con posterioridad a la Primera Guerra Mundial, la necesidad de creación de un nuevo partido distinto del SPD, el ejercicio de la huelga como instrumento revolucionario, la propuesta de la Asamblea Constitucional, la función del Consejo Obrero y la necesidad de una revolución económica de tipo socialista que incluyera a los campesinos. Y finalmente expuso las tareas para la acción político-revolucionaria del partido:

1. Extensión del Consejo de Obreros.

2. Lucha económica desde los Consejos Obreros, desde donde se debería dar solución a los problemas económicos.

3. Conquista del poder mediante una acción progresiva, lo cual implica abandonar la opción de hacerlo de un solo golpe, que a su vez implicaba la conquista de la totalidad de las instituciones estatales y su posterior custodia.

4. Proporcionar educación y disciplina a la masa popular previa a la toma de las instituciones, sin confundirse con el aprendizaje del ejercicio del poder, ubicado en un momento posterior a su toma.

5. Conquista de la revolución proletaria desde abajo, desde su base.

Como ha destacado Fernando Prieto, Rosa Luxemburgo tenía más confianza en la clase proletaria que en el partido proletario. De allí sus críticas al "blanquismo" del proyecto de Lenin: "Blanquismo es la creencia en que un pequeño grupo muy disciplinado puede dirigir a las masas para hacer la revolución” (Rodríguez, 2018, p. 154). Luxemburgo

defiende que no hay que luchar por objetivos que no sean compartidos por las masas, que no hay que manipular a las masas sino educarlas para que alcancen la madurez política que las haga capaces de cumplir su misión en la historia. [Y afirma, criticando a Lenin:] Libertad es siempre la libertad del que piensa de distinta manera. (Rodriguez, 2010, p. 69)

Luxemburgo fue asesinada el 15 de enero de 1919. Quedó en el archivo de su vida y obra una carta donde relata sus últimos días. De acuerdo con Pablo Slavin (2012, p. 238): 
En una carta a su amiga Clara Zetkin, Rosa Luxemburgo comenta cómo transcurrían los que, a la sazón, serían sus últimos días: “...Estoy atada a la redacción y cada día permanezco en la imprenta hasta medianoche, entre otras cosas para supervisar el ajuste; además, en estos tiempos convulsos no llegan hasta las $10 \mathrm{u} 11$ de la noche las noticias y consignas, ante las que hay que reaccionar de inmediato. A ello se suman casi todos los días desde la mañana temprano las reuniones y conferencias; entretanto otras asambleas y para variar, cada varios días, la urgente advertencia desde 'centros oficiales' de que Karl (Liebknecht) y yo somos perseguidos por sicarios, de modo que no debemos dormir en casa, sino que tenemos que buscar cada noche refugio en un lugar diferente...”.

\section{Historia: reforma o revolución}

La reconstrucción de la obra de Rosa Luxemburgo en relación con la evolución del debate en torno a la revolución y la reforma, propio de los movimientos y partidos políticos de izquierda anteriores y posteriores a la Primera Guerra Mundial, permite avanzar hacia la construcción de una crítica política de la institución del partido en el entorno del surgimiento de los totalitarismos, la Segunda Guerra Mundial, la Guerra Fría y la caída del muro de Berlín. Todo eso desemboca en una nueva época en la que la extinción del partido, el auge de los movimientos sociales, la falta de política a largo plazo y las mediaciones que eliminan los subsistemas para reformar al sistema son algunos de los factores que impiden la obtención de las exigencias sociales proletarias. Esta evolución política e histórica permite señalar la vigencia de Luxemburgo en el tema de los principios de construcción del partido, proceso que será examinado a continuación.

A finales del siglo xIX se desarrolló un proceso político que buscaba impulsar a las masas hacia movimientos y partidos políticos que se manifestaron en huelgas y denuncias laborales. Esto provocó la intervención y mediación de los Estados, según lo expone Eric Hobsbawm:

La década de 1890 fue el decenio en que los gobiernos europeos reconocieron la existencia política de movimientos obreros sólidamente organizados.

[...] Por primera vez un ministro británico, lord Rosebery, en 1894, sintió 
la necesidad de intervenir personalmente para dirimir una disputa entre empleadores y trabajadores. [...] Aquel mismo año el gobierno francés, dio un paso que conmocionó a los partidos políticos del trabajo, o por lo menos a los socialistas, hasta la médula. Nombró a un socialista de cuarenta años, Alexandre Millerand, al frente del Ministerio de Comercio. Hasta entonces, y durante muchos años, los socialistas habían dado por sentado que nunca participarían en el gobierno ni formarían parte de él hasta que la revolución o una huelga general hubiesen depuesto al capitalismo, o por lo menos hasta que un partido socialdemócrata hubiese obtenido una victoria electoral en solitario. Ideológicamente, esta fue la crisis que inició la historia política del trabajo en el siglo xx. (Hobsbawm, 2011, p. 406)

La acción política perseguida por Millerand y Bernstein se fortaleció dentro del movimiento obrero y sus partidos al basar su propuesta en la inocuidad de la acción revolucionaria dentro de las luchas laborales. Las denuncias contra el reformismo provinieron por parte de los precursores de la revolución. Es el caso de Rosa Luxemburgo, quien en su obra ¿Reforma o revolución? criticó los postulados de Bernstein que negaban la concepción del materialismo histórico y la autodestrucción del capitalismo e invitaban a la reforma gradual del sistema. En ese marco, se suponía que movimientos que oscilaran en dirección a las cooperativas de consumo, los sindicatos y el ejercicio gradual de la democracia participativa lograrían una adaptación al capitalismo y la eliminación de las crisis económicas. Luxemburgo desenmascaró el objetivo final de la reforma: la atenuación de las circunstancias históricas que generan las crisis del capitalismo y la alteración del cambio de orientación para evitar así el afianzamiento del movimiento revolucionario, la configuración del socialismo y la institucionalización del sufragio universal por fuera de la figura de la democracia liberal.

En 1890 se esperaba la caída del capitalismo como consecuencia de la misión histórica de los movimientos y partidos obreros, de acuerdo con la propuesta del Manifiesto comunista, en abierto rechazo al movimiento histórico propuesto por los revisionistas. A pesar de su negación de la revolución, debe aclararse que estos no aspiraban a provocar una crisis de los movimientos obreros. Y tampoco es posible afirmar que la persistencia del capitalismo fuera consecuencia de la construcción teórica y práctica de la política de la época. El asunto debe examinarse como un cambio en la dirección del proyecto. 
Los movimientos laboristas y la consciencia de clase no son proyectos, sino, en una determinada fase de la producción social, características lógicamente necesarias y políticamente casi inevitables de la clase que reúne a hombres y mujeres asalariados. El término proyecto se aplica más al socialismo, es decir, a la intención de sustituir el capitalismo por un nuevo sistema económico y una nueva sociedad (Hobsbawm, 2011, p. 408).

Para 1907 el congreso en Stuttgart de los partidos de la Segunda Internacional dio votación a la iniciativa presentada por Luxemburgo y Lenin: la huelga general como respuesta a la guerra que estaba por estallar. Los demás partidos socialistas creyeron que la guerra no llegaría, por lo que no era forzoso seguir a la Segunda Internacional en ese punto, sino que simplemente cada partido tenía que tomar una postura clara.

La Primera Guerra Mundial (1914-1919) tuvo por causas principales el sistema centroeuropeo y la respectiva colonización de las periferias, elementos visibilizados por Luxemburgo en su obra El folleto Junius (originalmente titulado La crisis de la socialdemocracia alemana). Allí la autora muestra a la Primera Guerra Mundial como el ejercicio del capitalismo en la acción invasora de los Estados europeos, la carrera armamentista, la rivalidad ruso-austriaca en los Balcanes y la crisis interna de AustriaHungría. En opinión de Luxemburgo dicha acción bélica abrió un tajo en la carne del movimiento obrero el 4 de agosto de 1914: la capitulación de la socialdemocracia alemana ante las pretensiones nacionalistas del Gobierno, que quedaron así inscritas dentro de la política del partido. La revolución pasó entonces a un segundo plano, inmolada en el altar del espíritu nacional: se olvidó el acuerdo de Stuttgart y desapareció del mapa la huelga general.

En este periodo se presentó también la Revolución rusa de 1917, la cual dio el golpe de gracia al zarismo. Durante el mes de febrero de ese año Petrogrado sufrió una transformación política: las fuerzas militares se aliaron a las huelgas laborales que reclamaban pan y fin a la autocracia. El resultado fue la obtención de la jornada laboral de ocho horas y la democratización del sistema político. La revolución continuó en busca del desenlace de la guerra, la ejecución de la reforma agraria y la consolidación de una Asamblea Constituyente, la cual fue disuelta en 1918. 
Rosa Luxemburgo agitó la reactivación de la revolución considerando las bondades y falencias de la transformación política y económica de Rusia, postulando a la república democrática como la primera etapa de la revolución y buscando la consolidación de la segunda etapa, la política internacional. El asunto de la posesión de la tierra fue objeto de especial reflexión, al estar esta bajo la propiedad de grandes terratenientes que impedían el curso de la revolución. Por eso la autora postula la configuración de la economía en cooperativas de trabajo asociado para evitar la redistribución individualista de la tierra. El olvido y la eliminación de la Asamblea Constituyente fueron las causas generadoras de la posterior inmovilidad del Estado socialista y evidenciaron el desinterés por la democracia de origen revolucionario. El sufragio universal, respaldado por los ideólogos de la revolución, se contrapuso a la decisión de rechazar la representación popular.

Con la derrota de Alemania, la destitución del Káiser y la constitución de la República de Weimar, se instauraron nuevamente la integridad territorial, la defensa del gobierno socialdemócrata, los derechos y deberes político-sociales, las conquistas laborales - como es el caso de las ocho horas-, los contratos colectivos y los subsidios de desempleo. Todo eso permitió introducir los principios del welfare State que recogía el revisionismo. La solución del conflicto se consolidó a través de un tratado de paz que permitió a las grandes potencias vencedoras establecer un "cordón sanitario" para impedir el "contagio" de la Revolución rusa. Por último, el Tratado de Versalles dispuso en sus artículos 231 y 232 la responsabilidad alemana de la guerra, de modo que esta nación quedó obligada a pagar la reparación posterior.

La Primera Guerra Mundial dejó como consecuencia la división del SPD, hecho evidenciado en la fundación del Partido Comunista Alemán entre el 30 de diciembre de 1918 y el 1 de enero de 1919. Allí Luxemburgo daría sus últimas declaraciones políticas al exponer el programa del partido retomando el Manifiesto comunista en relación con la función histórica del proletariado, la revolución, pero ubicada en el contexto de la posguerra. El capitalismo continuó su tránsito, mientras que la facción socialdemócrata terminó por aislarse del proceso revolucionario, que siguió el curso de la Revolución rusa, cuya historia nos enseña su conquista del poder y el olvido de la democracia como base del partido. El 15 de enero de 1919 Karl Liebknecht y Rosa Luxemburgo fueron asesinados por órdenes de la socialdemocracia. El consecuente resentimiento produjo en el Partido Comunista Alemán una postura sectaria de subordinación a la Segunda Internacional, hecho rechazado por el alumno y heredero de 
Luxemburgo, Paul Levi. Es el periodo de caída del proceso revolucionario, pues el SPD dio acogida a los postulados revisionistas de Bernstein y sus pactos con el empresariado como opción de defensa ante la revolución social.

Por otra parte,

a pesar de que las cosas fueron muy distintas después de 1917, el capitalismo en sus principales baluartes no estaba amenazado ni por el colapso final ni por una revolución limitada a los países de la periferia del sistema. La revolución soviética nunca viajó desde Petrogrado hasta Berlín [...]. De ahí que los fundamentos de la simbiosis reformista permanecieran sólidos [...]. Todo lo que se perdió en las guerras fue la prosperidad que proporcionaba los medios para las necesarias concesiones a los movimientos obreros. (Hobsbawm, 2011, p. 413)

La crisis de las tijeras, en la cual los precios de la economía agrícola entraron en conflicto con los precios de la economía industrial, generó una falta de desarrollo en la economía y la cultura de Rusia. Stalin reunió las cuatro repúblicas - Rusia, Ucrania, Bielorrusia y Transcaucasia - en abril de 1923, y selló su unificación bajo el nombre de Unión de Repúblicas Socialistas Soviéticas (URSs). Lenin se oponía al nacionalismo de partido promovido por Stalin, pero la hora de su muerte, en enero de 1924, lo alcanzó antes de poder publicar algún tipo de comunicado oficial. La caída de la Bolsa de Wall Street el 23 de octubre de 1929 marcó el comienzo de la inevitable crisis económica. A largo plazo eso significó el acceso a un periodo histórico de reformismo a escala mundia.

\section{Conclusiones}

La propuesta de Rosa Luxemburgo se contextualiza en el debate del revisionismo durante la Primera Guerra Mundial. Aquí se examinó su rechazo de la reforma como construcción teórica que permitía un camino alterno a la revolución, por no ser más que una forma de evitar la consolidación del proyecto socialista expuesto en el marco de la tradición marxista. La perspectiva de Luxemburgo permitió una comprensión prematura de los acontecimientos de la primera y la segunda guerras mundiales en los partidos políticos de carácter revolucionario durante sus procesos de división y consolidación. Así, la acción revolucionaria fue caracterizada como aquella que perseguía la remoción total del sistema político y económico vigente a través de un partido 
político que tendría por finalidad la construcción de un modelo de Estado socialista, mediante una pedagogía de masas, con el aporte de la agitación propia de la huelga social y procurando el ejercicio del poder desde abajo hacia arriba y la democracia. Mientras tanto, la construcción reformista, que Luxemburgo rechazaba, perseguía la permanencia del sistema capitalista con reformas graduales que proporcionaban mejoras sociales sin necesidad de destruir el sistema.

La reflexión sobre la dicotomía reforma-revolución en la obra de Luxemburgo permitió resaltar la necesidad de pensar las fases revolucionarias como partes de una actividad política que necesariamente tuviera que coincidir con la democracia. Incluso generar un modelo político alterno que tome como fundamento las circunstancias históricas.

Finalmente, los hechos históricos paralelos y posteriores a la vida y obra de Luxemburgo permitieron corroborar la importancia del análisis y de la advertencia realizada por la autora en relación con el revisionismo, cuya implementación deja como resultado la eliminación del socialismo propuesto por la autora.

\section{Referencias}

Beltran, A. (2009). Acercamiento a la vida y la obra de Rodney Arismendi. La Habana: Editorial Universitaria.

Berbel, S., Cárdenas, M. y Paleo, N. (2014). Ideas que cambian el mundo: una mirada desde la izquierda feminista. Valencia: Cátedra.

Dunayevskaya, R. (1985). Rosa Luxemburgo: la liberación femenina y la filosofía marxista de la revolución. México: FCE.

Dussel, E. (2010). Veinte tesis de política. Caracas: El Perro y la Rana.

Frölich, P. (1976). Rosa Luxemburgo, vida y obra. Madrid: Fundamentos.

Gambina, J., Rajland, B. y Campione, D. (comp.) (2002). Pensamiento y acción por el socialismo. América Latina en el siglo XXI. Buenos Aires: Clacso.

Hobsbawm, E. (2011). Cómo cambiar el mundo. Marx y el marxismo 1840-2011. Barcelona: Crítica. 
Luxemburgo, R. (1970). The socialisation of society. Berlín: Gesammelte Werke.

Luxemburgo, R. (1976). Obras escogidas. Bogotá: Pluma.

Luxemburgo, R. (1986 [1900]). Sobre el militarismo y la política colonial en el Congreso International París. Recuperado de https://www.marxists.org/espanol/ luxem/1900/9/17.htm

Luxemburgo, R. (1999). El orden reina en Berlín. S. L.: Red Vasca Roja.

Luxemburgo, R. (2003 [1906]). Huelga de masas, partido y sindicato. Madrid: Fundación Federico Engels.

Luxemburgo, R. (2017a). La crisis de la socialdemocracia. Madrid: Akal.

Luxemburgo, R. (2017b). Reforma o revolución. Madrid: Akal.

Perdices de Blas, L. y Gallego, E. (2009). Mujeres economistas: las aportaciones de las mujeres a la ciencia económica y a su divulgación durante los siglos XIX y XX. Madrid: Editorial del Economista.

Rodriguez, J. (2010). Trótsky y el trotskysmo original: la persecución del fundamentalismo estalinista. Bogotá: Universidad de La Sabana.

Rodríguez, J. (2018). La revolución Bolchevique: De Lenin a Stalin. Bogotá:Universidad de La Sabana.

Sánchez, G., Álvarez, A. y Figueroa, S. (2014). Reproducción, crisis, organización y resistencia: a cien años de La acumulación del capital de Rosa Luxemburgo. México: Clacso.

Slavin, P. (2012). Una aproximación al pensamiento de Rosa Luxemburgo. Anales de la Facultad de Ciencias Jurídicas y Sociales, 9(42), 229-240. 